\title{
The role of phototherapy in neonatal nonphysiologic jaundice as a risk factor for nephrolithiasis
}

\author{
$\underline{\text { Alireza Eskandarifar }}{ }^{1}$, Majid Mansouri ${ }^{2}$, Ibrahim Gaderi ${ }^{3}$, Samira karami ${ }^{4}$ \\ 1. Assistant Professor, Department of Pediatric, Faculty of Medicine, Kurdistan University of Medical Sciences, Sanandaj, \\ Iran, (Corresponding Author), Tel: +988733285910, Email: are1345@yahoo.com ORCID: 0000-0001-9173-359X \\ 2. Associated Professor, Department of Pediatric, Faculty of Medicine, Kurdistan University of Medical Sciences, Sanandaj, \\ Iran. ORCID: 0000-0002-9865-9430 \\ 3. Associated Professor, Department of Epidemiology and Biostatistics, faculty of Medicine, Kurdistan University of Medical \\ Sciences, Sanandaj, Iran. ORCID: 0000-0002-2303-1657 \\ 4. Medical Student, Student Research Committee, Kurdistan University of Medical Sciences, Sanandaj, Iran
}

\begin{abstract}
Background and Aim: one of the known complications of phototherapy in the treatment of jaundice in newborns is the reduction of serum calcium and the cause of this phenomenon is still not well defined. The aim of this study was to investigate the effect of phototherapy on increasing calcium urinary excretion and to answer the question whether phototherapy can be associated with increased urinary excretion of calcium as a risk factor for nephrolithiasis? Materials and Methods: In this cross-sectional study 77 infants less than 2 weeks of age with normal weight who were hospitalized for non-physiologic jaundice were enrolled in a sampling study. These infants lack systemic underlying disease and were not treated with Antibiotics - No serum therapy and blood transfusion. Urine specimens were taken at the time of admission and 48 hours after phototherapy of newborns and ca, $\mathrm{cr}$ in urine was measured. Then, the ratio $\mathrm{Ca} / \mathrm{Cr}$ was calculated. Finally, the obtained data was entered into SPSS 19 software and analyzed.
\end{abstract}

Results: Average random urine $\mathrm{Ca} / \mathrm{Cr}$ ratio before phototherapy was $0.38 \pm 0.03$ and the average random urine of $\mathrm{ca} / \mathrm{cr}$ after phototherapy was $0.674 \pm 0.26$. The difference between the mean of $\mathrm{Ca} / \mathrm{Cr}$ ratio of neonates with jaundice before and after phototherapy was significant $(\mathrm{P}<0.001)$ in $49.4 \%$ of neonates hypercalciuria was seen $(\mathrm{Ca} / \mathrm{Cr}>0.8)$. Conclusion: According to the findings of this study, which indicates an increase in urinary excretion of calcium, phototherapy in newborns can be considered as a risk factor for the incidence of hypercalciurea and nephrolithiasis.

Keywords: Phototherapy, Nephrolithiasis, Neonatal, Non-physiologic jaundice, Urinary stone

Received: July 7, 2019

Accepted: Sep 25, 2019

How to cite the article: Alireza Eskandarifar, Majid Mansouri, Ibrahim Gaderi, Samira karami. The role of phototherapy in neonatal nonphysiologic jaundice as a risk factor for nephrolithiasis. SJKU 2020; 24 (6): 140-147

Copyright $(\mathbb{C} 2018$ the Author (s). Published by Kurdistan University of Medical Sciences. This is an open access article distributed under the terms of the Creative Commons Attribution-Non Commercial License 4.0 (CCBY$\mathrm{NC}$ ), where it is permissible to download, share, remix, transform, and buildup the work provided it is properly cited. The work cannot be used commercially without permission from the journal 


\section{نقش فوتوترايى در نوزادان مبتلا به زردى غير فيزيولوزيك بهعنوان يك ريسك فاكتور براى سنكهاى ادرارى}

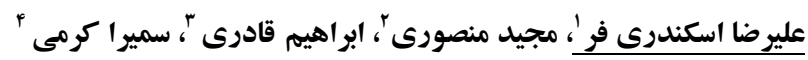

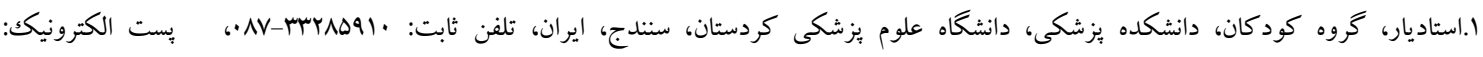
........1-9/Vr-rهqx : are1345@yahoo.com r. r.

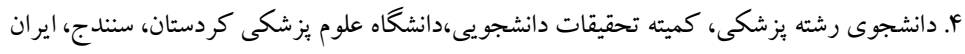

جـكيده

زمينه و هدف: يكى از بيمارىهاى شايع دوران نوزادى ايكتر و يا زردى است كه در موارد شديد مهمترين اقدام درمانى استفاده

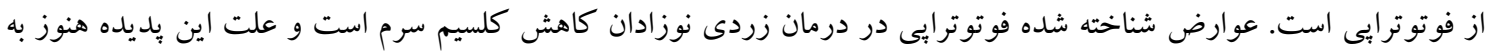

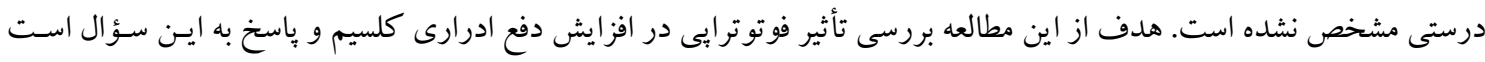

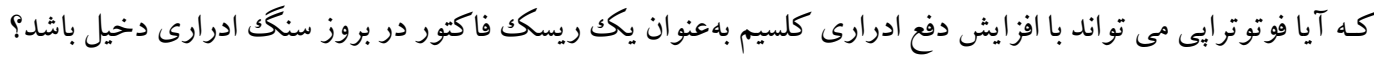

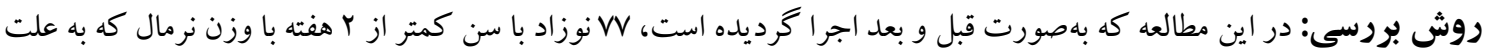

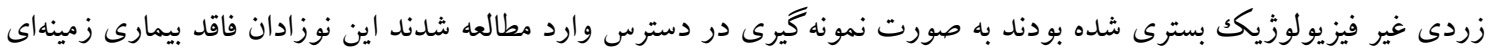

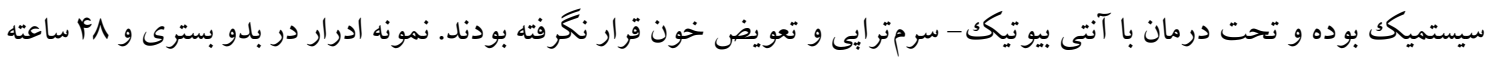

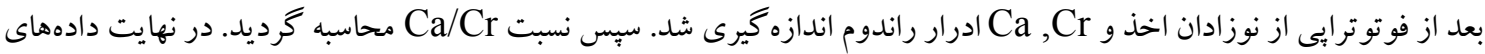

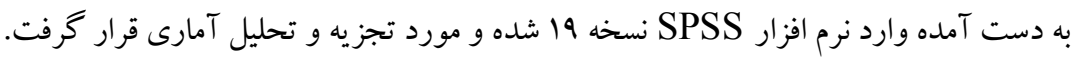

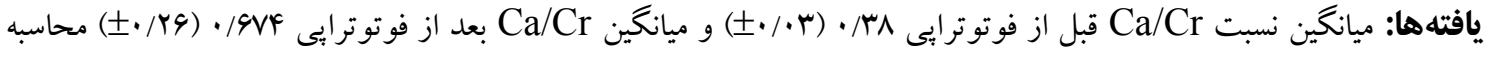

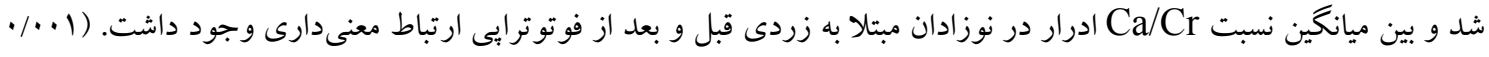

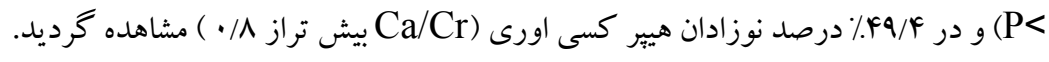

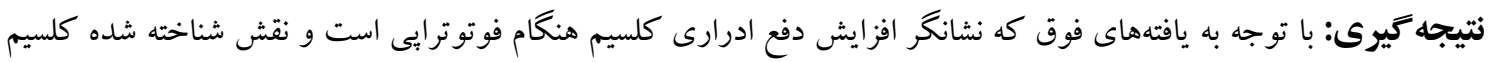

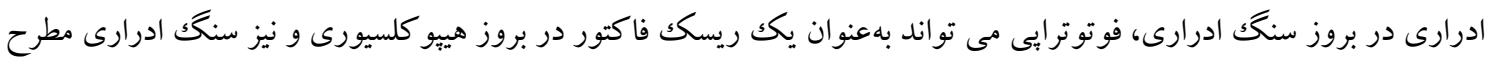
كلمات كليدى: فوتوترايى، دفع كلسيم ادرارى، نوزادان، زردى غير فيزيولوزيكك ،سنگك ادرارى

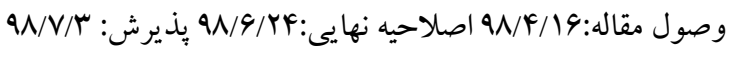


يكى از عوارض فوتوترابى كه اخيراً مطرح شده است هيبو كلسمى وهيير كلسيورى است كه علت دقيق آن هنوز مشخص نيست. بروز هييو كلسمى در نوزادان تحت فوتو ترايى ارتباطى به سطح ويتامين D و كمبود آن ندارد و به نظر مىرسد كه ناشى از كاهش ترشح ملاتونين و يا افزايش دفع ادرارى كلسيم در طى فوتوترايى باشد (ب-4) ).

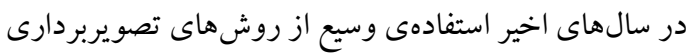
به خصوص سونو گرافى منجر به تشخيص سنگكهاى ادرارى در سنين بايين و حتى در طى دورهى شيرخوارى و نوزادى شده كه اكثر آنها از نوع سنگكهاى كلسيمى بوده و هيير كلسيورى يك علت شناخته شده در بروز آنها

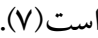
در صورتى كه فوتوترايى در ميزان دفع ادرارى كلسيم تأثير داشته باشد فوتوترايى مىتواند بهعنوان يكك ريسك فاكتور فئور در بروز سنگك ادرارى در سنين هايين مطرح شود و اين مطالعه با هدف باسخ به اين سؤال انجام شده است.

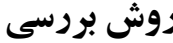

نوع مطالعه بهصورت قبل و بعد است. جامعه مورد مطالعه

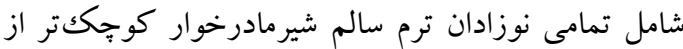

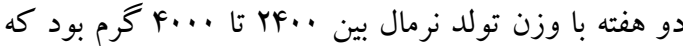

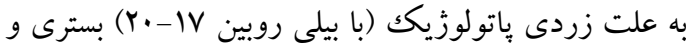
تحت فوتوترابى استاندارد قرار مى گرفتند در صورت وجود بيمارى سيستميك از قبيل سبسيس، تجويز آنتىبيوتيك،

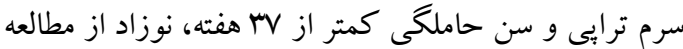
حذف مىشد. اين مطالعه در بخش نوزادان بيمارستان بعثت

$$
\text { سنندج در سال وq انجام شد. }
$$

روش جمع آورى اطلاعات نيز به اين صورت بود كه ابتدا نوزادان توسط دستيار متخصص كودكان از نظر معيارهاى ورود و خروج بررسى مىشدند. در صورت وجود بيمارى

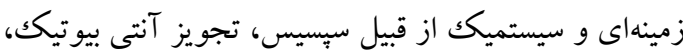

\section{مقدمه} زردى (ايكتر) از بيمارىهاى شايع دوران نوزادى است كه به علت افزايش سطح سرمى بيلىروبين است. بيلىروبين در اثر كاتابوليسم همو كلوبين در دستكاه رتيكولو اندو تليال

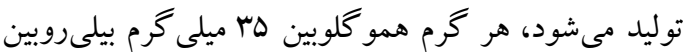
توليد مى كند. نماى بالينى افزايش بيلىروبين زردى است، زردى در نوزادان به دو دسته فيزيولوزيك و باتولوزيكك تقسيم مىشود: زردى فيزيولوزيكك در اغلب نوزادان رخ مىدهد و بهصورت افزايش خفيف سطح سرمى بيلىروبين غيرمستقيم در روز سوم زندگى است و از با ميلى گرم بيشتر نمىشود درصورت افزايش بيشتر و يا ديرتر در سطح بيلىروبين بخصوص در نوزادان نارس بايد به فكر علل زمينهاى بود كه اين دسته از موارد زردى تحت عنوان زردى غير فيزيولوزيك قرار مى

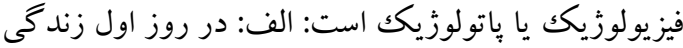
به لحاظ بالينى آشكار باشد. ب: سطح بيلى روبين در هر

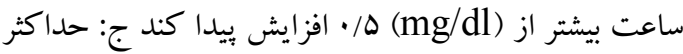
مقدار بيلى روبين در نوزاد ترم بيشتر از (mg/dl) rا باشد. د: بخش مستقيم بيلى روبين بيشتر از (mg/dl ها 1/ باشد. ه:

اخر بزرگى كبد طحال و آنمى وجود داشته باشد(Y-1). صرفنظر از علت زردى، در اكثر موارد درمان آنها با بـان فوتوترايى انجام مى شود. فوتوترايى نوزادان توسط لامبٍ

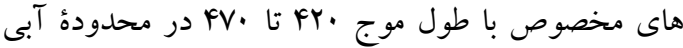
بيشترين تأثير را داشته كه با واكنشهاى فوتو كميكال و ايزومرسازى منجر به افزايش دفع بيلى روبين از طريق صفرا

و ادرار و كاهش سطح سرمى بيلى روبين مى شود (Y-1). فوتوترايى داراى عوارض شناخته شدهاى از قبيل: مدفوع شل، بثورات يوستى، افزايش درجه حرارت بدن، كم آبى،

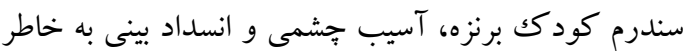

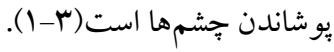




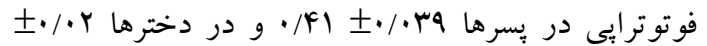

هץ/· بود كه تفاوت معنىدارى بين دو گروه وجود نداشت

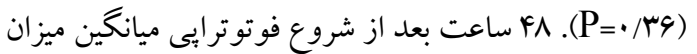
Ca/Cr

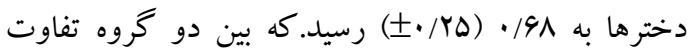
معنى

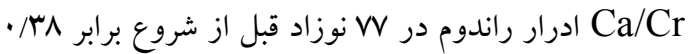
( ) • (

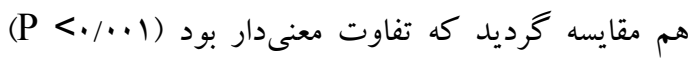

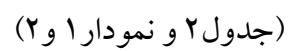
در نمودار ب گراف نقطهاى ميزان Ca/Cr ادرار در نوزادان مبتلا به زردى قبل و بعد از فوتوترايى ارائه شده است. با توجه به اينكه ميزان Ca/Cr بيش از ^/ • در نوزادان بهعنوان

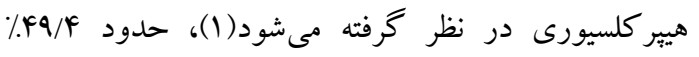
نوزادان بعد از شروع فوتوترايى دجار هيبر كلسيورى شده

بودند.
سرمترايى، تعويض خون و اختلالات متابوليك نوزاد از مطالعه حذف مى شد. يكك نمونهُ ادرار در بدو بسترى و يكك نمونه \& 1 ساعت بعد از شروع فوتوترايى از نوزاد اخذ مى شد نمونه ادرار بهوسيله كيسه ادرار جمع آورى و بلافاصله به آزمايشگاه فرستاده مىشد. كلسيم توسط اسبكتو فتومترى و كراتينين به روش جاوا بر حسب mg/dl اندازه گيرى و نسبت Ca/Cr محاسبه گرديد. در نهايت نيز دادهها وارد نرم افزار 19 SPSS شدند. براى مقايسه متغيرهاى كمى بين دو كروه از تست تى مستقل و براى مقايسه متغير كيفى قبل و بعد از فوتوترايى از تست تى زوجى استفاده شد.

يافتهها

در اين مطالعه W نوزاد ترم- شيرمادر خوار با سن كمتر از هفته و بدون بيمارى زمينهاى، وارد مطالعه شدند. از اين

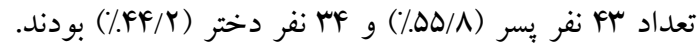
ميانگين ميزان Ca/Cr در ادرار راندوم قبل از انجام

\begin{tabular}{|c|c|c|c|c|c|c|c|}
\hline $\mathrm{P}$ & $\mathrm{Z}$ & ميانه & انحر اف معيار & ميانگين & تعداد & جنسيت & \\
\hline \multirow[t]{2}{*}{$\cdot / V 19$} & $-\cdot$ Maf &.$/ . Y \Lambda$ &.$/ .49$ &.$/ \cdot F 11$ & kr & يَر & \multirow{2}{*}{ نسبت Ca/Cr قبل از انجام } \\
\hline & &.$/ . Y q$ & $\cdot / r$ & ט./. & $r F$ & دختر & \\
\hline \multirow[t]{2}{*}{$\cdot / v \cdot 1$} & $-\cdot / N V \Delta$ & $\cdot / V \Delta$ & $\cdot / \pi q$ & .194 & $\mathrm{Fr}$ & ل يسر & \multirow{2}{*}{ نسبت 2 فو توترايى از انجام } \\
\hline & & $\cdot|\Lambda|$ & $\cdot / r \Delta$ & $\cdot 191$ & $\mu F$ & دختر & \\
\hline
\end{tabular}

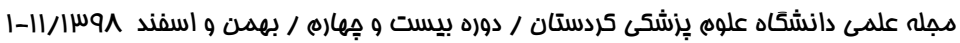




\begin{tabular}{|c|c|c|c|c|c|c|c|}
\hline $\mathrm{P}$ & Z & انحراف معيار & تفاونين & ميانه & ميانگين & تعداد & متغير \\
\hline \multirow{2}{*}{$<\cdots \cdots$} & \multirow{2}{*}{-V/GYF } & \multirow{2}{*}{. TVD } & \multirow{2}{*}{-. } & $\cdot / \cdot Y \Lambda$ & $\cdot / \cdot r \Lambda$ & W & قبل Ca/Cr \\
\hline & & & & $\cdot / \mathrm{V} 9$ & $.19 \mathrm{VF}$ & W & Ca/Cr \\
\hline
\end{tabular}

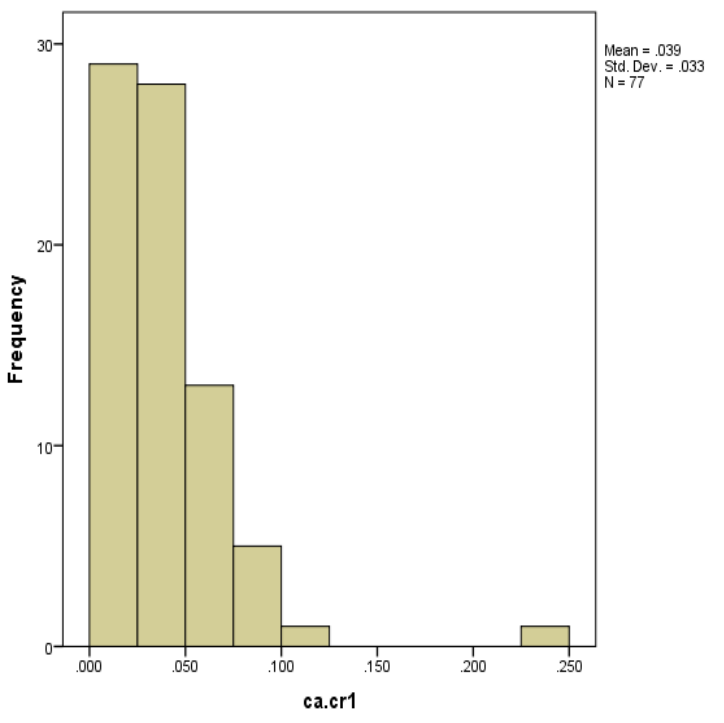

نمودار ا. ميزان فراوانى نسبت Ca/Cr ادرار قبل از فوتوترايى 


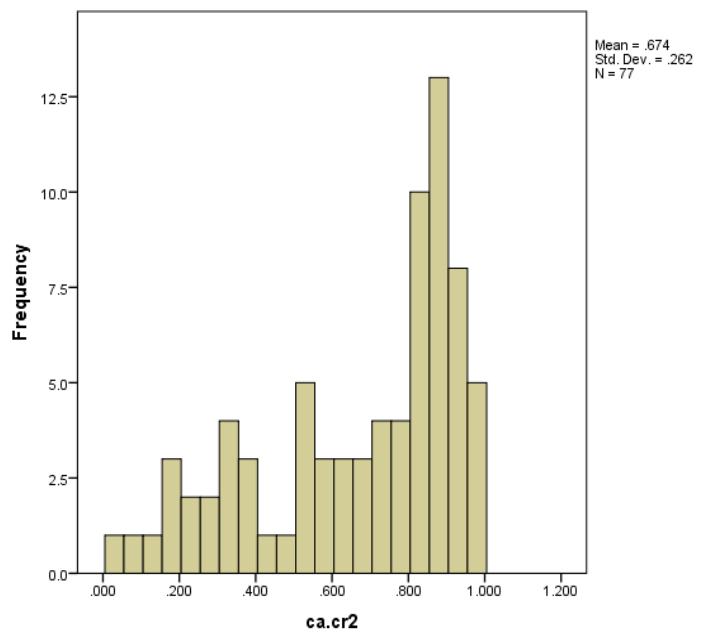

نمودار r. ميزان فراوانى نسبت Ca/Cr ادرار بعد از فوتوترايى

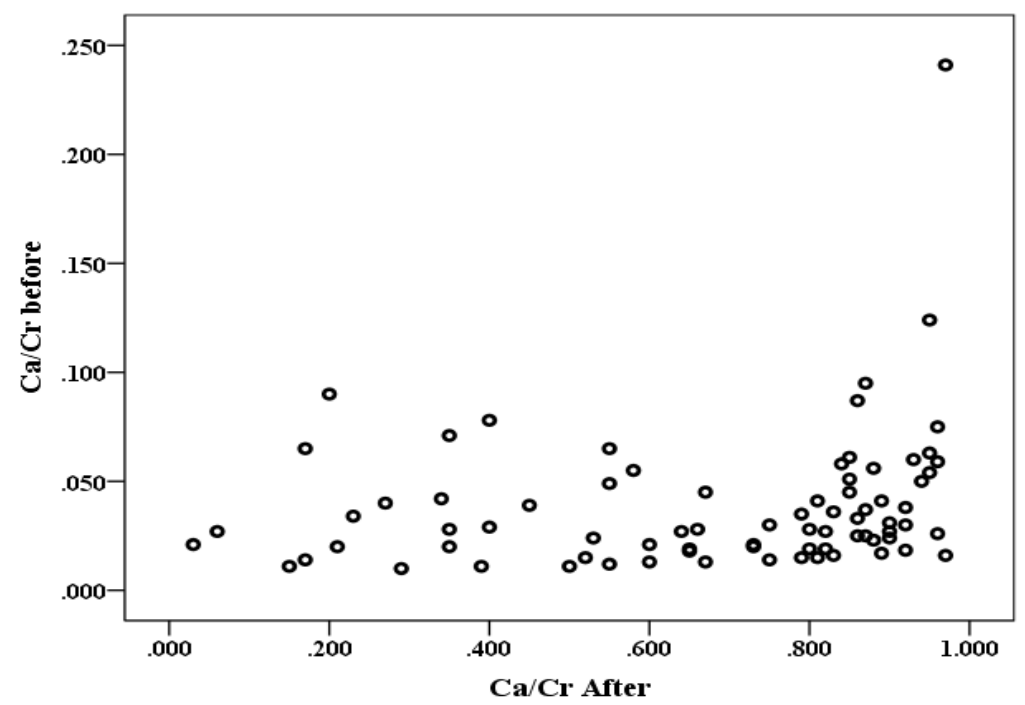

نمودار r. گر اف نقطهاى ميزان Ca/Cr ادرار در نوزادان مبتلا به زردى قبل و بعد از فوتوترايى

در مطالعه ى كه در نيويوركك در سال 1991 روى موشهاى تازه متولد شده انجام شــ، مـوشهــاى مو اجهـه يافتـه بـا نـور فلورســت دجـار هيبو كلسـمى شـدند كـه مطـرح كنــده اثر كاهش ترشح ملاتونين در بـروز هييو كلسـمى بـود(4). البتـه

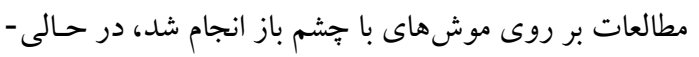

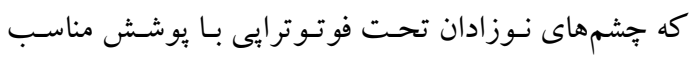

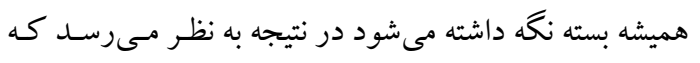

$$
\begin{aligned}
& \text { همانطور كه در ابتدا اشاره شد هييو كلسمى و هيبر كلسيورى } \\
& \text { يكى از عوارض فوتوتر ابى است كه اخيراً مطرح شــده اسـت } \\
& \text { ولى دليل مشخصى براى بروز آن ذكر نشده است. مطالعه ى }
\end{aligned}
$$

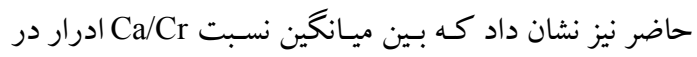

$$
\begin{aligned}
& \text { نوزادان مبتلا به زردى قبل و بعد از فوتو ترايى ارتباط معنى - }
\end{aligned}
$$

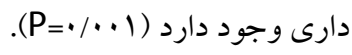




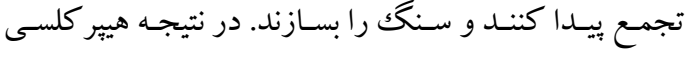

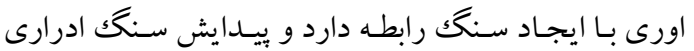

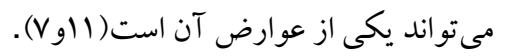

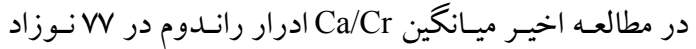

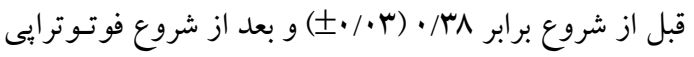

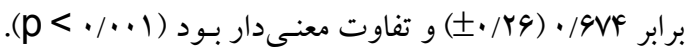

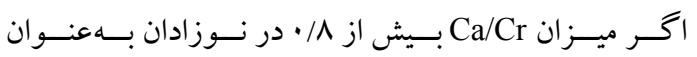

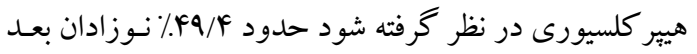
از شروع فوتوترايى دجار هيير كلسيورى شده بودند كه هيتيج

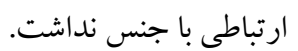

با توجه به يافتهاى مطالعه حاضر و ساير مطالعات كه نشانخر

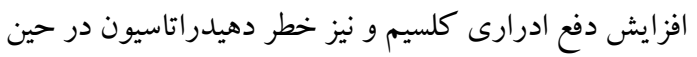

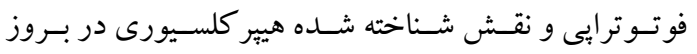

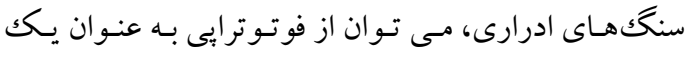

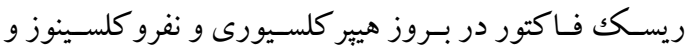
سنگ ادرارى نام برد.

\section{نتيجه كيرى}

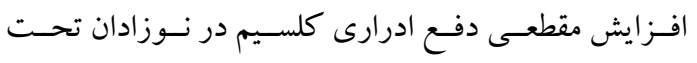
فوتوترايى اهميت توجه به وضعيت هيدراتاسيون نـوزاد حسين

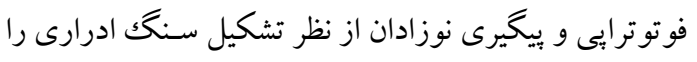

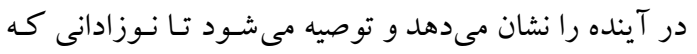

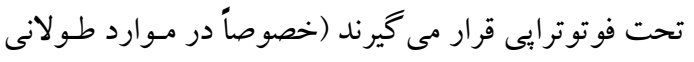

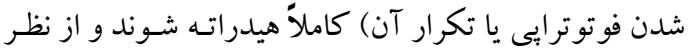
تشكيل سنگك ادرارى در آينده مورد بررسى قرار گيرند.

\section{تشكر و قدردانى}

از كار كنان بخش نوزادان بيمارستان بعثت سنتدج و دانشـكاه

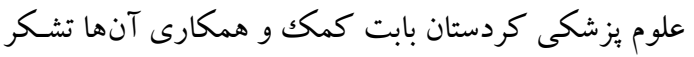

$$
\text { و قدردانى مىشود. }
$$

در انسان تاثير كاهش ملاتونين در بروز هييو كلسمى به عنوان عامل اصلى مطرح نباشد. در مطالعهى مشابهى كه توسط هومن وهمكاران ( ITMM )در دانشكاه علوم يزشكى ايران انجام شده است ونتايج ان در دو

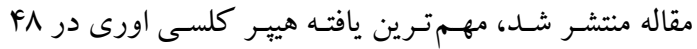

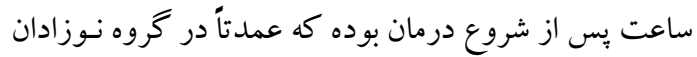

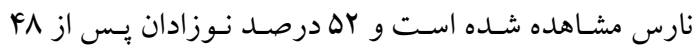
ساعت شـروع درمـان نسبت Ca/Cr ادرار بيشتر از ^/• را

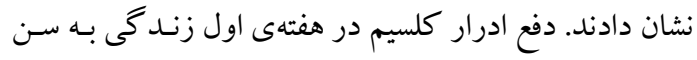

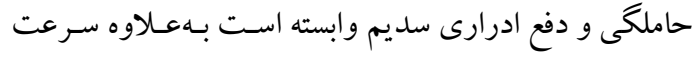

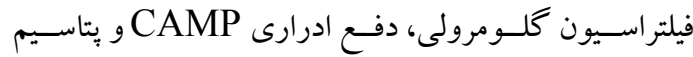

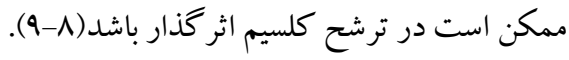
در مطالعه ديخرى كه توسط ايمانى وهكاران(

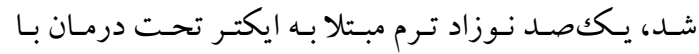
فو توتر ايى در شهر زاهدان مورد بررسى قرار گرفتنـد. در ايـن

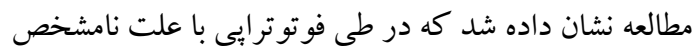

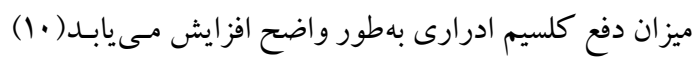
كه اين نتيجه با يافتههاى مطالعه ما مطابقت دارد.

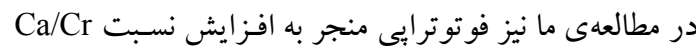

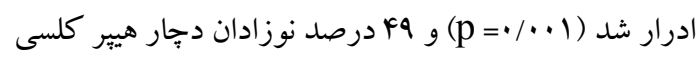
اورى شدند. در مطالعه ما سديم و اسمولالتيه عى ادرار اندازه

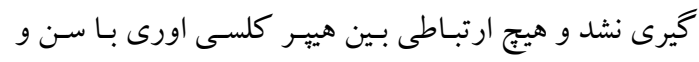

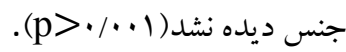

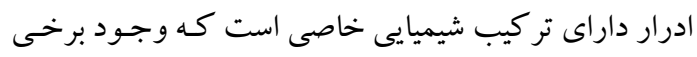

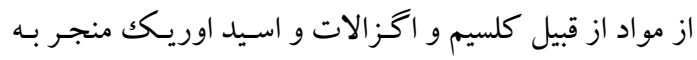
افزايش تشكيل سنگك و برخى ديخر مثل منيزيم و سيترات

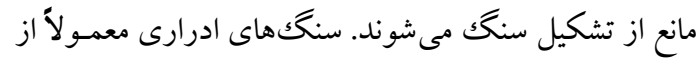

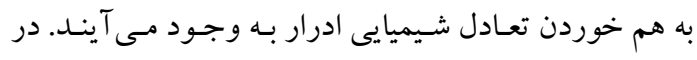

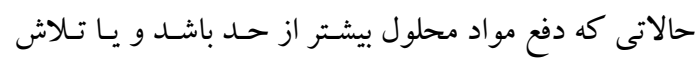

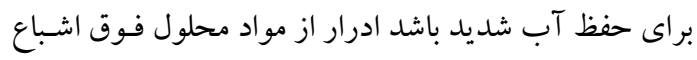

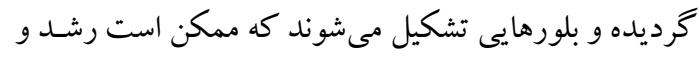




\section{Reference:}

1. Kliegmassn RM, Stanton B, Geme JS, Schor NF, Behrman RE. Nelson textbook of pediatrics. 20th edition, Elsevier,2016;871-876.

2. de Almeida MF, Draque CM. Neonatal jaundice and breastfeeding. NeoReviews. 2007; 8(7): 282-8.

3. Maisels MJ. Phototherapy: Maisels MJ, WatchkoJF, editors. Monograph in clinical practice: Neonatal Jaundice. 1st ed. Singapore: Harwood academic publishers. 2000; 177-203. 4. Eghbalian F, Monsef A. Phototherapy-induced hypocalcemia in icteric newborns. IJMS. 2015; 27(4):169-71.

5. Karamifar H, Pishva N, Amirhakimi GH. Prevalence of phototherapy-induced hypocalcemia, IJMS. 2015; 27(4):166-8.

6. Hakanson DO, Bergstrom WH. Phototherapy-induced hypocalcemia in newborn rats: prevention by melatonin. Science. 1981; 214(4522):807-9.

7. Ellis D. Avner,William E Harmon,Patrick Niaudet, et al, pediatric nephrology ( $7^{\text {th }}$ edition), springer. 2016;1821-1860.

8. Hooman N, Honarpisheh A. The effect of phototherapy on urinary calcium excretion in newborns. JPN. 2005; 20(9):1363-4.

9. Houman N, Taheri DN, Samaei H, Arab MH, Blood level and urinary excretion of calcium in neonates with nonphysiological hyperbilirubinemia under phototherapy, RJMS. 2009; 195 202.

10. Imani, Mahmoud; Sadeghi-bojd, Simin; Falahati, Fathmeh Khonamani; Moghadam, Alireza Ansari, Effect of Phototherapy Treatment on Urinary Calcium Excretion in Neonates with Jaundice in Zahedan, Iran, IJN. 2018; 4:61-65.

11. Asplin JR. Evaluation of the kidney stone patient. InSeminars in nephrology. 2008; 28, No. 2 : $99-110$. 